\title{
Health and Environmental Impacts of Waste Electrical and Electronic Equipment in the City of Kenge, DR Congo (2007 -2017)
}

\author{
Cush Ngonzo Luwesi ${ }^{1 *}$, Alexis Tohemo Lukamba ${ }^{2}$, Jean Richard Mukondo Mugodi ${ }^{3}$, Fi S Your \\ Mayamba Mukanza $^{4}$ and Bonaventure Lunga Pelende ${ }^{5}$ \\ ${ }^{1}$ Associate Professor, Faculty of Economics, Kenge, DRC \\ ${ }^{2,4}$ Assistant, ISTM / Mari e Queen of Peace Kenge, RD C \\ ${ }^{3,5}$ Assistant, Faculty of Agricultural Sciences, Kenge, DRC \\ *Corresponding author: Cush Ngonzo Luwesi, Associate Professor, Faculty of Economics, Kenge, DRC
}

ARTICLE INFO
Received: May 06, 2019
Published: May 28, 2019
Citation: Cush Ngonzo L, Alexis Tohe-
mo L, Jean Richard Mukondo M, Fi S
Your Mayamba M, Bonaventure Lunga
Pelende. Health and Environmental Im-
pacts of Waste Electrical and Electronic
Equipment in the City of Kenge, DR Con-
go (2007 -2017). Biomed J Sci \& Tech
Res 18(3)-2019. BJSTR. MS.ID.003144.

ABSTRACT

This study aims hazing for assessment the extent to which human health can be compromised by reckless behavior of human being white, with regards to the disposal of e-wastes, including Electrical and Electronic Equipment (EEE) wastes. Tea study Estimated entire 16 to 24 tons of e-wastes from teledu phones worm intend to the lies of Kenge about it. Besides, has 133.362 users their Phones Each year in this city, thus repre feels about 87 to $93 \%$ of the Total population holding entire 533,448 and 800.172 tele to 2007 phones from 2015, are finally qui f o u n d in the environment of this Kenge. The study also found heavy metals and toxic substances in EEE available components sed by Kenge residents, inevitably causes pollution and environment all deterioration in general, and food and water poisoning in particular. As a result, people's health is endangered due to the Lack of an environmentally sound management (ESM) of wastes to Regulate the disposal of EEE wastes in the environment. There is a need for provincial authorities in the field of ESM program for managing e-wastes in the province in general and the city of Kenge in particular.

Keywords: Health Impacts; Environmental Impacts; Waste; Electronic; Electrical Equipment

\section{Summary}

This head study was to assess the extent to which human health has been compromised by the irresponsible behavior of the man in the use of electrical and electronic equipment (EEE). Its acted materials and substances that cause environmental pollution in general, and food and water, heavy metals and toxic substances. Indeed, are residents of the town of Kenge sometimes use EEE which the waste is discharged into the environment due to lack of an Environmentally Sound Management (ESM). This waste of electrical and electronic equipment (WEEE or e-waste) dumped in the environment of Kenge is estimated between 16 to 24 tons of telephone waste. In addition, 133,362 users have telephones in the city of Kenge. They account for 87 to $93 \%$ of the total population of which 533,448 to 800,172 phones became waste in

the environment of the city of Kenge between 2007 and 2015. It is therefore recommended to the provincial authority to establish e-waste management program to stem the scourge of pollution that puts danger life thousands of people in the City of Kenge.

\section{Introduction}

Environmental issues and New Information and Communication Technologies (NICT) are at the forefrontofinternational, regional and national chronicles. On the one hand, the world is shaken by global warming due to the emission of greenhouse gases Deforestation and waste, with as corollaries drought and pollution (Luwesi 2017). On the other hand, the New Information and Communication Technologies (ICTs) are promising and revolutionist almost every 
aspect of human life [1]. These phenomena that are part of our reality, evolving in a dialectic that becomes their involvement in the physical well-being, social and economic population. The Information and Communication Technologies (ICT) revolution has been acclaimed as a social reference standard [2].

The e-waste program Africa of the Basel Convention notes that access to ICT has been identified as an indicator of the economic and social development of a country. "It was necessary to bite at all costs!" She said (Secretariat of the Convention Basel, 2012) [3]. However, like any two-sided medal, new technologies have always had their reverse, the revolution as not without perverse effects, like for u proliferation of electrical and electronic equipment (WEEE or "third-waste") years of the modern environment. This situation added was caused by unprecedented volumes of production and consumption of electronic products, especially personal computers, mobile phones and televisions and radio stations.

In some West African countries, antiquated EEEs are undergoing some form of basic recycling. However, several other parts of electronic waste cannot be managed properly and in occasion the accumulation of large volumes of hazardous waste in and around major rehabilitation centers [4]. In addition, some practices, such as open burning of cables and plastic parts, little Frit cause serious pollutant releases, that has the heavy metals and dioxins (Convention Secretariat Basel, 2012) [2]. The town of Kenge, which is situated years the province of Kwango, in DR Congo, does not escape this reality. It has become increasingly involved in the consumption of Electrical and Electronic Equipment (EEE), especially in the field of computing. The phenomenon WEEE must deserve special attention of researchers and social actors are as much as food, deforestation and erosion.

Unfortunately, studies are this kind are rare or even nonexistent. Thus, our study was guided by the following questions: can we establish between art e-waste and food, energy, water and health? The target population she knows and practice it ESM? If not, how is it doing business about the management of e-waste? What prevent be the health and environmental impacts related to e-waste management practices by local people? We trust that this study e will establish a link between e-waste and food, water, energy and health Kenge population in order to establish sound management systems of this specific waste stream to preserve the environment and the health of local communities.

\section{Literature Paper}

Since environmental change has been integrated into international policies and waste management has become an important component of environmental policies. This involves sorting, conditioning, collecting, transporting, storing, recycling, treating and disposing of waste, in addition to monitoring disposal sites (Minisanté 2015). In this regard, a substantial portion of utilized concepts inspired, sometimes very direct, of the Secretariat publication of the Basel Convention [2]. This document means waste, any substance that eliminates, or that intends to eliminate or is required to be eliminated under national laws (Secretariat of Basel Convention, 2012) [2].

The Electric and Electronic Equipment Waste (WEEE) are a category of waste defined by EU regulations as equipment using electric currents or electromagnetic fields, as well as production equipment, transfer and measurement of such currents and fields designed for use at a voltage not exceeding 1000 volts AC and 1500 volts DC [4]. The impacts of WEEE are legion in many areas of life and can be environmental, human and social consequences due to their export and treatment in an inappropriate way. In general, they little be grouped into six categories: soil and subsoil pollution, water contamination, contamination of air, the contamination of the food chain, the proliferation of the number of illegal landfills and the deterioration of working conditions.

The pollution has soil and subsoil has consequences of nervous system disorders, slotting sometimes neuropsychiatric problems, coma, death and underdevelopment of the brain, especially in children. These effects lead to rural exodus and the formation of slums in underdeveloped countries, sometimes generating cybercrime resulting from the recovery of electronic data housed in WEEE [6]. The second category concerns the contamination of water by infiltration into the water table and into rivers and in turn, the damage to the blood system. This impact makes the working conditions difficult, sometimes resulting in informal work. not registered by the State following the rejection of the person from the formal sector [6].

The third category is related to the contamination of the air by toxic fuels and the toxic ash heap, the effects of greenhouse gas on the environment and health are no longer to be doubted as well as the damage of the reproductive system, in terms of hormonal disorders, infertility [7]. The fourth category consists of the contamination of the food chain of agricultural products causing, among other perverse effects, the involvement of the respiratory system characterized by cough, infection, suffocation, asthma [8]. The fifth category is the increased quantities of waste product $s$ per capita over time thus causing a swarm of the number of illegal waste dumps in the world especially in Asia, South America and Africa, and exposing people to the kidneys, eyes, skin and bones. Gossart quoted by ADEME [7] stigmatizes that more than 100,000 tons of electronic waste were officially exported by the countries of the European Union 2007 towards development in the country. They suffer double trouble: not only are they the wrong side of the digital divide but import our digital hazardous waste that destroy their health and the environment [9].

Finally, the sixth category is linked to the deterioration of working conditions that have become bad and characterized by work accidents, stigmatization, harassment, the exploitation of employees by employers and, in most children [6]. These negative 
impacts of WEEE pose as risks likely to endanger human health social and environmental conditions. They can however be mitigated or sufficiently reduced by management environmentally sound. The latter is a set of practical measures to ensure that these hazardous wastes or other wastes as managed so that guarantee has the protection of human health of the controlled environment harmful effect that can avoids this waste [2].

This management usually consists in treating the waste by absorption or by chemical means. The materials adsorption hold the mercury to the surface through various types of chemical forces such as of hydrogen bonds, dipole-dipole interactions and Van Der Waals forces. The capacity of this adsorption depends on surface area, porosity and surface chemistry [10]. Among the adsorption materials, mention may be made of activated carbon and zeolite. Mercury and other heavy metals as well as organic substances adsorb to activated carbon (Bansal, 2005). The killed cost waste elemental mercury and mercury-containing waste are or contaminated with mercury are treated chemically, more main by the chemical conversion to mercury sulphide and amalgamation, $c$ 'is to D are forming a solid alloy with suitable metals [11].

According to Directive 2002/96/EC, WEEE can be classified into 10 categories. The first includes major appliances such as oven, hob. The second concerns small household appliances such as the coffee maker, the radio. The third is related to computer and telecommunications equipment. The fourth touches the material of the general public like the camcorder or television. The fifth category is the cell lighting equipment, except domestic lighting and incandescent lamps, which are subject to Articles 4 and 5 of Decree No 2005-829 of 20 July 2005 [12]. The sixth includes electrical and electronic tools, except for large fixed industrial tools. The seventh includes toys, and Equipements leisure and sport. The eighth relates to medical devices, except for implanted or infected products. The ninth category relates to monitoring and control instruments. The tenth is that vending machines [13]. Our study at focused on these categories of WEEE.

\section{Materials and Methods}

\section{Field of Study}

The town of Kenge, capital of Kwango Province in DR Congo, is located at $5^{\circ} \mathrm{S}$ latitude, $17^{\circ}$ East longitude and at an average elevation of $555 \mathrm{~m}$ above sea level [13]. It is in the tropical humid type region AW 3 or the tropical savanna (tropical savana) following the classification of Köppen (Figure 1). The town of Kenge rests on plateaus intersected by deep valleys, and sometimes hills, with sandy soil in a predominantly savannah configuration interspersed with forest galleries along streams. It has 153,290 residents in 15 neighborhoods [8].

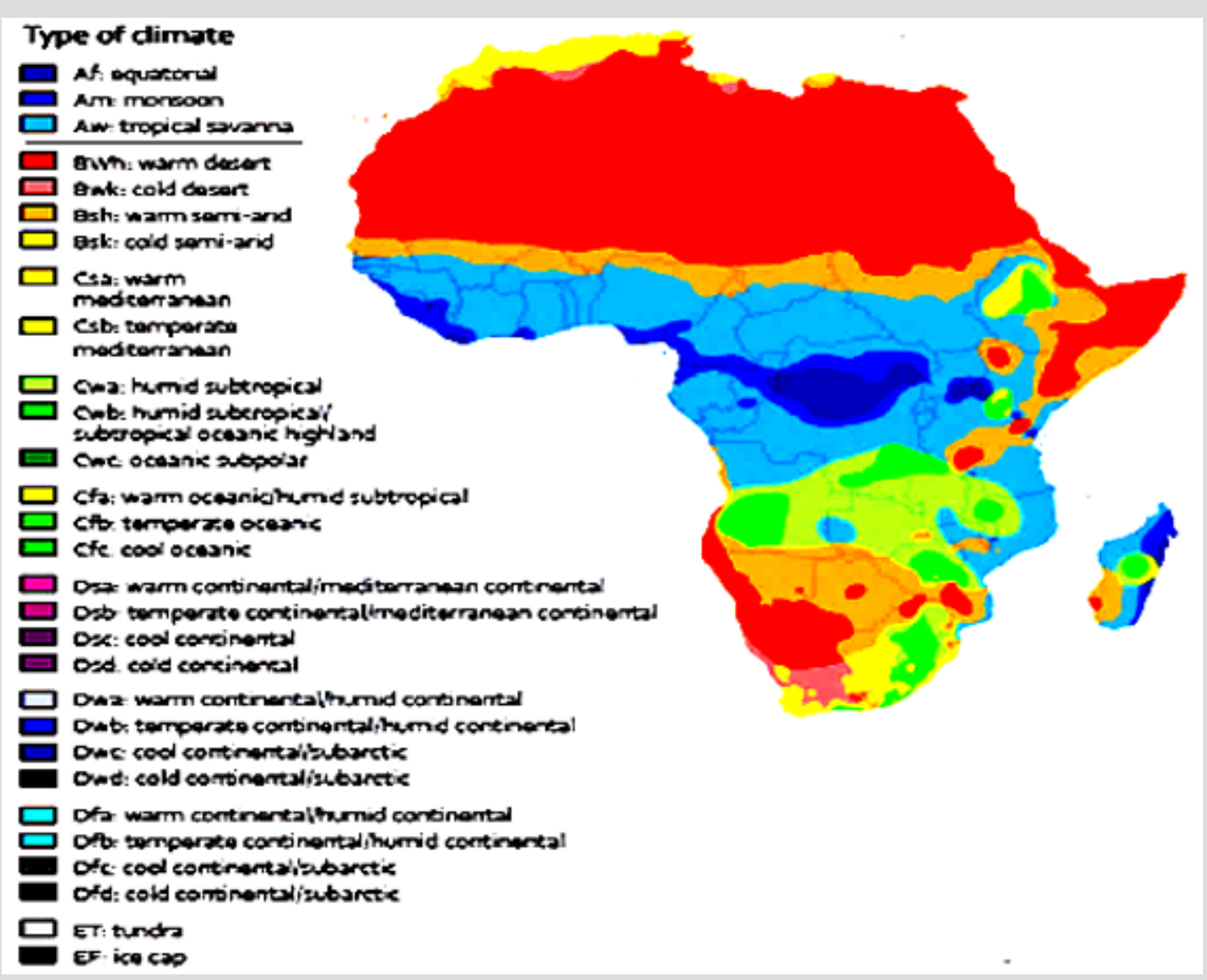

Figure 1: Map of Africa s climate s Van Koppen (Luwesi 2018). 


\section{Sampling and Data Collection Method}

Calculation of the Total Number of Respondents to Collect: We calculated the sample size according to them error rage option for estimates of population overall (National Contact Center Statistics Canada, 2010) and requested an estimate with a margin of error of $\pm 0.05(5 \%)$ and a $95 \%$ confidence level for the city of Kenge as a whole. As an estimation PRELI miner the proportion is not available during the we suppose that $\mathrm{P}=0$, and $\mathrm{u} 5 \mathrm{n} \mathrm{D}$ response rate of at least $50 \%$ is expected, or rather desired (Equations 1,2,3 and 4).

\section{a) Calculation of the initial sample size, $n_{1}$ :}

$$
\left.n_{1}=\left(Z^{2} \hat{P}(1-\hat{P})\right) / \alpha^{2} \quad \text { (Equation } 1\right)
$$

Or,

$Z$, is the critical value at the confidence level of $1-\alpha$, here equal to $95 \%$;

$\alpha$ is the threshold of the error, here it is equal to $5 \%$;

P, the proportion of individuals in the sample to be taken; and,

$\mathrm{n}_{1}$, the raw size of the sample.

b) Calculation of the size of the modified sample, $\mathbf{n}_{2}$ :

$$
n_{2}=\frac{N}{N+n_{1}}
$$

$\mathrm{N}$, represents the size of the population;

$\mathrm{n}_{1}$, raw sample size; and,

$\mathrm{n}_{2}$, corrected sample size considering the size of the population, here, the populational of city of Kenge (Table 1).

Table 1: No survey (k) of plots to be surveyed by neighborhood (City of Kenge, 2017).

\begin{tabular}{|c|c|c|c|c|}
\hline & Neighborhoods & Population (ni) & $\begin{array}{c}\text { Population to be } \\
\text { investigated (n) }\end{array}$ & K \\
\hline 1 & bakali & 24667 & 123 & 6 \\
\hline 2 & Congo & 15059 & 75 & 10 \\
\hline 3 & EPOM & 13665 & 68 & 11 \\
\hline 4 & Kapanga & 11834 & 59 & 13 \\
\hline 5 & Kikwit & 8806 & 44 & 17 \\
\hline 6 & Kenge3 & 4703 & 24 & 32 \\
\hline 7 & Mangangu & 5616 & 28 & 27 \\
\hline 8 & Manonga & 2348 & 12 & 64 \\
\hline 9 & Masikita & 11872 & 59 & 13 \\
\hline 10 & Mavula & 4210 & 21 & 36 \\
\hline 11 & Muni_kenge & 5495 & 27 & 28 \\
\hline 12 & Mukisi drilling & 13821 & 69 & 11 \\
\hline 13 & Wamba bridge & 15880 & 79 & 10 \\
\hline 14 & salongo & 3503 & 18 & 43 \\
\hline 15 & Yete & 11811 & 59 & 13 \\
\hline \multicolumn{2}{|}{ Total } & 153,290 & 766 & \\
\hline & & &
\end{tabular}

Referring to the Equation 2, we get $\mathrm{n}_{2}=383$

\section{c) Adjusts for Design Effect:}

$$
n_{3}=\text { Deff } \times n_{2}
$$

(Equation 3)

Or,

effect of $p$ the year report enters the variance Proton Exchange trilineage an estimate according to a plan given sample, and $v$ has variance sampling of the estimated a simple random sample (EAS) of even size e;

$\mathrm{n}_{2}$, corrected sample size

$\mathrm{n}_{3}$, adjusted sample size.

It should be noted that in a simple random sampling design, $\operatorname{deff}=1$, and usually, deff $\leq 1$ for a stratified design and deff $\geq 1$ for a cluster sampling design (Center of Contact N Statistics Canada, 2010). By applying the equation 3 we have $n=3383$ by asking it is an EAS, so deff $=1$. Adjustment for the response rate $(r)$ to determining the sample size final $n$ :

$$
n=\frac{n 3}{r}
$$

(Equation 4)

Where,

$\mathrm{n}$, size of the final sample to be investigated;

$\mathrm{n}_{3}$, sample size adjusted to the effect of the plan; and,

$r$, estimated response rate, here, $50 \%$. Hence, a size of the required sample is 766 individuals.

\section{Calculation of the Number of Respondents to be Collected} Per Neighborhood

At this level, we used the stratified sampling technique, the strata of which are the 15 neighborhoods in the Kenge City with a sampling fraction

$$
f=\frac{n}{N}
$$

(Equation 5)

Or,

f, the sampling fraction whose results are presented in Table 1;

$\mathrm{n}$, the sample size; and,

$\mathrm{N}$ the size of the population.

\section{Plots and People to Investigate}

According to an empirical inking, we agreed to investigate a person per plot, and, for this, it was necessary to calculate the sampling interval $(\mathrm{k})$ by the technique of systematic sampling is born by the equation e next (Equation 6):

$$
k=\frac{n}{n_{e}}
$$

(Equation 6)

Or,

$\mathrm{k}$ is the step of survey of plots (households) to investigate;

$\mathrm{n}$, the total size of the sample to be investigated; and,

$\mathrm{n}_{\mathrm{th}}$ the size of sub sample of each quarter. 
This technique was supplemented by the area sampling technique where the statistical units are the geographical areas, and routes that allowed us to mark the direction of the literary to follow for the investigation in this entity and in case, we choose the ordinal direction given by the government for the numbering of plots on each avenue. And, the data collection was carried out using a questionnaire the 766 respondents living in 15 districts of the city Kenge. As for the analysis and discussion of the number of telephones (Equation 7) and the proportion of telephone users (Equation 8), we made the estimation interval estimate, or confidence interval, at the critical value $u$ and to the accuracy of error $\alpha$.

$$
\text { at: } \bar{x}-u_{1-\frac{\alpha}{2}} \frac{S}{\sqrt{n}} \grave{a} \bar{x}+u_{1-\frac{\alpha}{2}} \frac{S}{\sqrt{n}} \quad \text { (Equation 7) }
$$

The confidence interval of a proportion the $1 \%$ risk threshold is represented by Equation 8:

$$
f_{n} \pm Z_{1-\frac{\alpha}{2}} \sqrt{\frac{p(1-p)}{n}}
$$

(Equation 8)

Or,

$\mathrm{f}_{\mathrm{n}}=$ estimator proportion in the population;

$\mathrm{P}=$ Proportion of the studied sample;

$\mathrm{Z}=$ critical value at the confidence level $1-\frac{\alpha}{2}$;

not= sample size studied

\section{Analytical Techniques}

This study is descriptive and analytical because it describes and analyzes the behavior of users of EEE vs household WEEE. It is retrospective as it focuses on knowledge and practical skills of the population of the configuration of study. Finally, it's a fluke forward, in that it focuses on the consequences of these social practices. Quantitative analysis was used to relate the different variables, measures or necessary parameters used to highlight the theme. It took place in two components: descriptive analysis and inferential analysis. The descriptive analysis was used to condense the survey results in statistical parameters, particularly in mean, standard deviation and percentage, to derive are the characteristics of the sample. The inferential analysis consisted of a hypothesis test based on the Chi-square test $[14,15]$.

This has verified the dependency relationship between the geographical configuration (districts) where the respondent lives and is aware of the Environmentally Sound Management (ESM), firstly and secondly, between knowledge of ESM and the local social practices of e-waste management destination of this waste and the knowledge of the risks of this waste by the inhabitants of the city of Kenge compared to yours locations (neighborhoods). The chi-square test (Chi 2 or $\square^{2}$ ) was used to verify the links between knowledge of adequate on risks linked waste and their geographical configuration. This head inferential analysis at allowed to test the null hypothesis that there was no relation entre the expected distribution of knowledge of equated on e-waste (E) and distribution observed geo their localization graphic (0). Thus, the century following assumptions have been testing: of $\mathrm{E}$ and $\mathrm{O}$

$$
\mathrm{H}_{0}: \mathrm{E} \neq 0 \text {, there is a significant difference entre distributions }
$$

$\mathrm{H}_{1} \mathrm{E}=\mathrm{O}$, There are not significant difference between the $\mathrm{E}$ and $\mathrm{W}$ of distributions

From an analytical point of view, the chi-square statistic (Khi 2 or $\square^{2}$ ) is represented by the following formula (Equation 9):

$$
\chi_{d d l ; p}^{2}=\sum \frac{\left(E_{j}-O_{i}\right)^{2}}{O_{i}}
$$

Where,

$E_{i}$, the $i^{\text {th }}$ actual expected distributions knowledge of the respondents on e-waste

$\mathrm{O}_{j}$, the $\mathrm{j}^{\text {th }}$ observed effective da ns distribution geographical configuration s respondents

$\mathrm{ddl}$, the degree of freedom (equal to nk)

$n$, the total number of the sample

$k$, the number of estimated parameters (equal to the number of factors)

$\mathrm{p}$, the signification rate (equal to the probability of failure of Ho)

The chi-squared statistic $\left(\mathrm{Chi}^{2}\right)$ was tested at a significance level of $5 \%$ ( $p=0.05$ ) using computer software SPSS June $1.0 \mathrm{M}$ and Microsoft Excel 2013 to give meaning the explanatory descriptions relation by setting the variables of study to better INTERPRET results the study.

\section{Presentation of Results}

This study consisted of:

a) Identify the producers of e-waste in the town of Kenge

b) Estimate the volume e-waste

c) Identify the socio-economic and environmental impacts of their management practices

d) Evaluate the knowledge of the respondents on the GER of e-waste as well as the social practices of local management of WEEE.

\section{Some Sociodemographic Characteristics of the Respon- dents}

The survey covered 400 miles (52\%) and 366 females (48\%), 27 of whom were not educated. (3.5\%), 74 having a level of primary study (9.7\%), having a post 319 with primary secondary studies s incomplete es (41.6\%) level, 253 with a secondary level of education $(32.0 \%)$ and 93 with a higher level or university level (12.1\%). 


\section{WEEE Production}

This involved identifying the users of EEE likely to be producers of e-waste. And to this end, the 766 respondents, a respondent had, from 2007 to 2017, at least one of the following EEA : Telephone (689 in total, 90\%), radio (403 in total, 53\%), Televise positions (200 in total , or $26 \%$ ) computer (120 in total , or $17 \%$ ), DVD player (80 in total or $10 \%$ ), or printer (50 in total , or $7 \%$ ). With regard to the end of life of these EEE with the user, it should be noted that 8 telephones of $10(80 \%), 2$ radios out of $10(20 \%), 3$ TV out of 10 (30\%), 1 in 10 computers (10\%), 1 in 10 (10\%) and 1 DVD player are discarded, or rather, converted into e-waste disposed between 2007. A stimulation of the volume of e-waste in the City of Kenge reveals that a respondent has an average of 7 telephones in ten years, i.e. between 2007 and 2010 (standard deviation = 5,987). That is to say that in the entire population of the city of Kenge, it is likely that an individual has 6 to 8 phones (at 1\% significance level).

Furthermore, there is a $99 \%$ probability to see 76 to $84 \%$ of these phones be converted to e-waste, or 4 to 6 phones out of 7 in ten years. In addition, 133. 362 users have telephones in the town of Kenge, and 533. 448 to 800. 172 phones become waste, since 2007. Assuming an average of 30 grams of mass per phone, we can estimate 16 to 24 tons of telephone waste in the environment of the city of Kenge, from 0.10 to $0.16 \mathrm{~kg} /$ individual.

\section{Knowledge of Pre and Social Practices of E-Waste Man- agement}

Based on the survey data analyzed, if we assume that the Kenge population is environmentally sound, there would be a smaller probability than 0.0005 (i.e. less than 5 chances in 10000) that we obtain a sample such as which was (see meaning within the hatched box Table 2). In addition, the calculated Chi-square value (149.970) is greater than that of the table with the degree of freedom equal to 14 and the risk threshold of $5 \%$ (6.57) and the threshold of $1 \%$ (4.66). The difference is therefore highly significant: the null hypothesis is rejected according to the population of the city of Kenge knows the GER (Figures 2 \& 3).

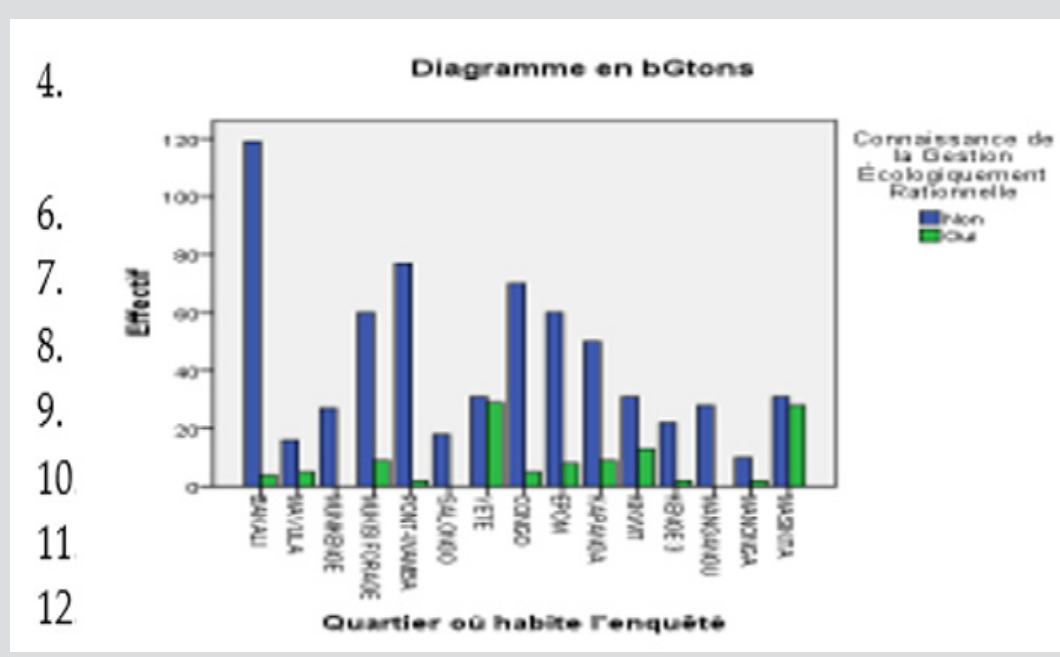

Figure 2: Connaissance sur la GER des DEEE a Kenge.

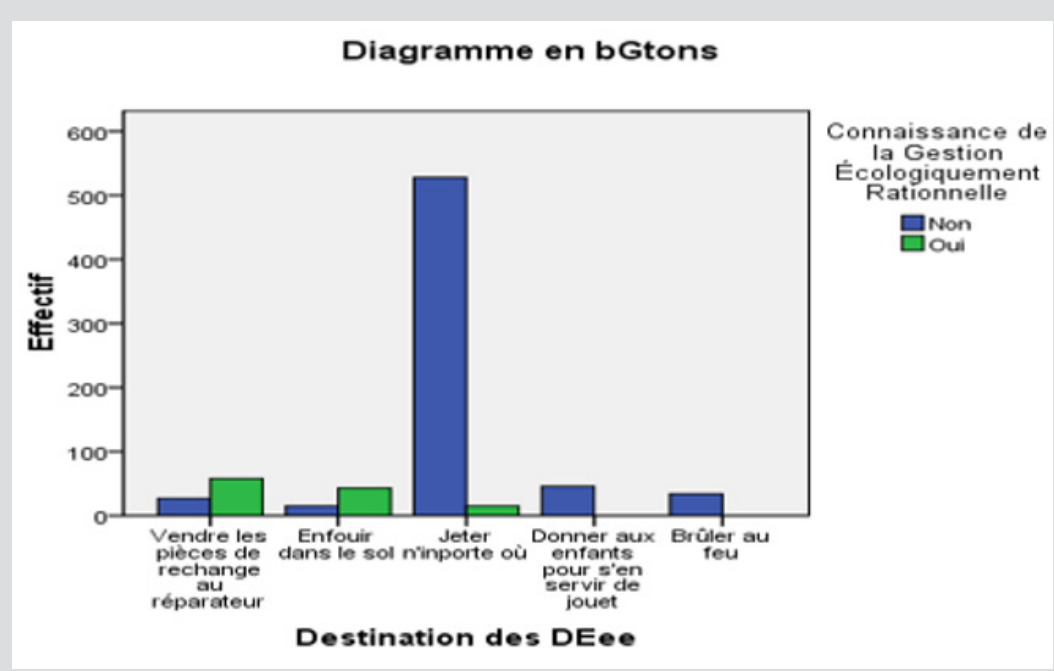

Figure 3: Connaissance sur la GER et élimination/destination finale des DEEE. 
On the other hand, can we say that the management practices (the final disposal) of the e-waste of the population of the city of Kenge depend on the knowledge of the GER? If they depend on it, in any case, there is only less than 5 chances out of 10,000 (Table 2) that this is true at the degree of freedom 4 and the thresholds $5 \%$ and $1 \%$. Otherwise, there is no link between their e-waste management practices and the knowledge of GER; it is that the GER does not influence these local management practices of e-waste (Table 3).

Table 2: Knowledge of GER by Kenge residents in 2017.

\begin{tabular}{|c|c|c|c|}
\hline & Value & dOF & $\begin{array}{c}\text { Asymptotic significance } \\
\text { (bilateral) }\end{array}$ \\
\hline Chi-square of Pearson & $149.970^{\text {a }}$ & 14 &, 000 \\
\hline Likelihood ratio & 141.835 & 14 &, 000 \\
\hline $\begin{array}{c}\text { Number of valid } \\
\text { observations }\end{array}$ & 766 & & \\
\hline
\end{tabular}

Note: Source: Authors (2018).
Table 3: Knowledge of ESM and final disposal of e-waste in K en ge in 2017.

\begin{tabular}{|c|c|c|c|}
\hline & Value & doF & $\begin{array}{c}\text { Asymptotic significance } \\
\text { (bilateral) }\end{array}$ \\
\hline Chi-square of Pearson & $422,585^{\mathrm{a}}$ & 4 &, 000 \\
\hline Likelihood ratio & 341.57 & $\mathrm{~s} 4$ &, 000 \\
\hline $\begin{array}{c}\text { Number of valid } \\
\text { observations }\end{array}$ & 766 & & \\
\hline
\end{tabular}

Note: Source: Authors (2018).

\section{Health and Environmental Impacts of E-Waste}

About the impacts of e-waste, we looked to the negative impacts of e-waste, and the level of knowledge of the population about the risks to health and the environment. It appears from the crude that only $18.5 \%$ of respondents had to recall the fact that e-waste makes have dirty media; $81.5 \%$ reported no negative impact (Figure 4) and (Table 4).

Table 4: Knowledge of PRE and the risks associated with e-waste in 2017.

\begin{tabular}{|c|c|c|c|}
\hline & Value & dOF & Asymptotic significance (bilateral) \\
\hline Chi-square of Pearson & $435,905^{\text {a }}$ & 1 &, 000 \\
\hline Correction for continuity & 430.506 & 1 &, 000 \\
\hline Likelihood ratio & 348.542 & 1 & \\
\hline Fisher's exact test & & & \\
\hline Number of valid observations & 766 & & \\
\hline
\end{tabular}

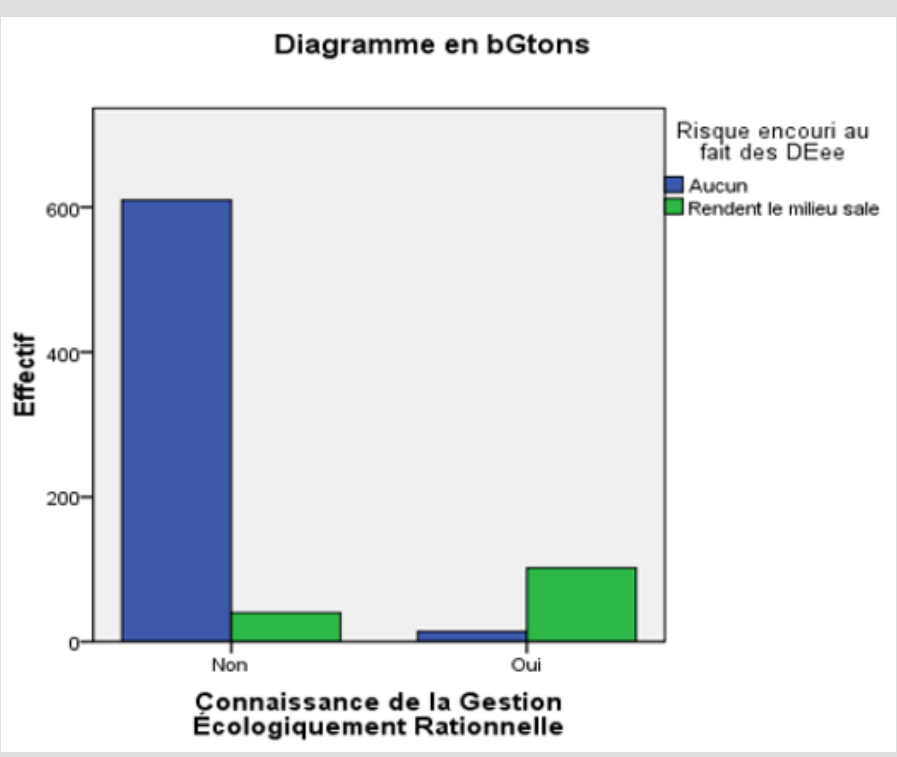

Figure 4: Connaissance sur la GER et risques liés aux DEEE.

The Chi-square analysis of significance reveals that there are only five chances on 10000 (Table 5) that this hypothesis is true. In addition, the value of the calculated Chi-square (435.905) is greater than that of the table with the degree of freedom equal to 1 and the risk threshold of 5\% (0.098) and the threshold of 1\% (0.0157). The difference is therefore highly significant: We reject the null hypothesis that the population of the city of Kenge knows the risks of e-waste. That's why they took options to give children to use as toys, or to pile them with other waste and burn them in the fire, or to bury them in the ground or to throw them away. anywhere that may prove to be dangerous methods. 
Table 5: Effects toxic to some substances in EEE Health.

\begin{tabular}{|c|c|c|}
\hline Substances & Health effects & Current Presence in DEEs \\
\hline $\begin{array}{l}\text { Brominated flame } \\
\text { retardants }\end{array}$ & $\begin{array}{l}\text { Although they are less studied than polycyclic chlorine derivatives, } \\
\text { their toxicity is likely to be close to them, so they are suspected of } \\
\text { having endocrine, neurotoxic and toxic properties for reproduction. }\end{array}$ & $\begin{array}{l}\text { Printed circuit board, connectors, plastic } \\
\text { coatings, cables }\end{array}$ \\
\hline $\begin{array}{l}\text { Cadmium and its } \\
\text { compounds }\end{array}$ & $\begin{array}{l}\text { The toxicity depends in particular on the solubility of the compounds. } \\
\text { Some are classified toxic (inhalation and ingestion). Carcinogens } \\
\text { (category } 2^{*} \text { ); mutagenic (cat. } 2^{*} \text { ) and toxic for reproduction (fertility } \\
\text { and development / (cat. } 2^{*} \text { ) after inhalation of toxic effects may } \\
\text { be observed on kidneys and bones (demineralization) as well as } \\
\text { bronchial and prostatic cancers. }\end{array}$ & $\begin{array}{c}\text { Printed Circuit Board Components, Cathode Ray } \\
\text { Tubes, PVC Stabilizers }\end{array}$ \\
\hline \multirow{2}{*}{$\begin{array}{l}\text { Lead and its inorganic } \\
\text { compounds }\end{array}$} & $\begin{array}{l}\text { Lead compounds are classified as harmful by inhalation and ingestion, } \\
\text { accumulating in the body and toxic to reproduction (fertility and } \\
\text { development, Cat } 1^{*} \text { ). }\end{array}$ & $\begin{array}{l}\text { Soldering of printed circuit boards, Glass } \\
\text { components of cathode ray tubes, }\end{array}$ \\
\hline & $\begin{array}{l}\text { These compounds exert their effects on many organs including the } \\
\text { blood, the nervous system and the kidneys. Carcinogenic effects are } \\
\text { also suspected. }\end{array}$ & Welding and glass fluorescent tubes \\
\hline Nickel and its compounds & $\begin{array}{l}\text { Some nickel compounds are classified as allergenic for the skin } \\
\text { and carcinogenic by inhalation. The effects depend in part on their } \\
\text { solubility. They cause skin allergies. Rhinitis and asthma. Cancers of } \\
\text { the sinuses and bronchi are also described in some in some uses. }\end{array}$ & \\
\hline \multirow{2}{*}{$\begin{array}{l}\text { Mercury and its inorganic } \\
\text { compounds }\end{array}$} & \multirow{2}{*}{$\begin{array}{l}\text { Mercury is classified as toxic by inhalation. It accumulates in the body. } \\
\text { The effects of repeated exposure are primarily related to the nervous } \\
\text { system. }\end{array}$} & Thermostat \\
\hline & & Sensors, Relays and Switches, Fluorescent Lamps \\
\hline \multirow{3}{*}{$\begin{array}{l}\text { Beryllium and its } \\
\text { compounds }\end{array}$} & \multirow{3}{*}{$\begin{array}{l}\text { They are classified as very toxic by inhalation and toxic by ingestion, } \\
\text { irritants for the skin, the eyes and the respiratory and cutaneous } \\
\text { allergenic ways. Finally, they are classified as carcinogenic by } \\
\text { inhalation (category } 2^{*} \text { ). Even with very little consultation they can } \\
\text { cause serious damage to the bronchi and lungs of allergic and / or } \\
\text { irritative origin (berylliosis). }\end{array}$} & $\begin{array}{l}\text { Motherboards printed circuit board connectors, } \\
\text { monitors }\end{array}$ \\
\hline & & Relay \\
\hline & & Switches, X-ray tube windows \\
\hline
\end{tabular}

\section{Discussion of Results}

\section{WEEE Production}

All the waste mentioned here comes from households. There is no data on the exact quantity of e-waste on the configuration of our study, as it is the same in France where it does not exist either Reliable data on the quantity of waste from an delimited ICT in France, thus the estimations in the domain set to 450000 tons annual amount of Dèceites eliminate [16,17]. Data from the register electronic the waste sector area Ademe [6], 134295 tons teammates technology farming information and telecommunications were collected in 2009 in a purpose recovery, about $2.1 \mathrm{~kg}$ per French. By these, 19034 tons were collected from the professionals. The collection in the Household groin therefore equivalent to 115261 tons.

The results of this study indicate that a respondent has provided an average of 7 phones since 2007 (SD = 5.987). That is to say that in the entire population of the city of Kenge, it is likely that an individual has 6 to 8 phones and this with a risk of only $1 \%$ to deceive us and, 76 to $84 \%$ of these phones have a $99 \%$ probability of being converted to e-waste, i.e. 4 to 6 phones. And, as 87 to $93 \%$ of the population of the city of Kenge have telephones, 133,362 users who have telephones, 533,448 to 800172 phones have become waste since 2007. Assuming an average of 30 grams of mass per telephone, we can estimate 16 to 24 tons of telephone waste in the Kenge city environment, from 0.10 to $0.16 \mathrm{~kg} /$ individual.

\section{Knowledge of PRE and Social Practices of E-Waste Management}

The concern was whether the population of the study area was aware of what was meant by environmentally sound management (ESM), and what they were doing with e-waste (social practices). To this end, $84.9 \%$ of respondents admitted that they did not know about Ecologically Rational Management, compared to $15.1 \%$ who knew it. As for the social practices vise versa e-waste most investigated declares throw e-waste anywhere (70.9\%). However, $11.1 \%$ sell spare parts to repairers, $7.6 \%$ flush them into the ground, $6.0 \%$ give them to children to use as toys and $4.4 \%$ burn them to the fire $(4 \%)$.

\section{Socio-Economic and Environmental Impacts of E-Waste}

Most respondents in Kenge City believe that there is no danger from e-waste $(81.5 \%)$ and still others think that they simply make the environment dirty. As the situation arises, we can assume then that the population of the city of Kenge knows the risks of e-waste. It should also be noted that the population of the city of Kenge in particular, as noted by Alainet [18] for the African continent, is thus exposed to the environmental and public health concerns that may be generated by electronic waste. Because, once built, a computer [for example] contains lead, cyanide, and other substances harmful to the environment (Cordier, 2003). Screens contain many substances: lead and heavy metals, such as barium, strontium 
and sometimes zirconium. These dangerous chemical substances generate a high pollution and health risks for [the one] who handles them. However, Silicon Valley Toxic [19] quoted by Lassalle [20], notes that during its useful life, a treatment informatic poses General not problem of mission of toxic substances. As electronic waste by against these teammates are potential hyphenation many after toxicants if the management of the end of life of these Equipment is not assure adequate.

Thus, with the exception of the practice of selling spare parts to the repairer (11.1\%), which may pose less risk, it goes without saying that the practice of burning with fire $(4.4 \%)$ opted for the population of the town of Kenge is not without danger of pollution of the atmosphere, as Potelle justifies it (year) , says Lassalle [20], noting that certain practices, for example in case of incineration at insufficiently high temperature, brominated flame retardants produce dioxins and furans [21]. And, however, giving WEEE to children to use as a toy $(6.0 \%)$ is another common practice of the population of the Kenge city even though Alainet [18] makes a disturbing remark when it states that exposure to lead and mercury in children and pregnant women is of concern. Even at low levels of exposure these metals are extremely toxic. Moreover, this mania, or rather this carelessness, of the population of the city of Kenge to throw the e-waste anywhere (70.9\%), or to bury them in the ground $(7.6 \%)$, is yet another problem that is not referring to [22-30].

This seemingly innocuous behavior is fraught with consequences, and in the light of the analysis, this population is unaware of the nature, toxicity and impacts, or negative effects on their health. Yet Lassalle [20] EMPHASISI does the toxicity of some natures EEE component products such as electronic cards used for the understanding of the device, are made of copper, epoxy resin (thermosetting plastic) and fiber glass on which electronic components are soldered and which contain silicon and many other components in like arsenic, gallium, germanium, antimony and welding. is a mixture of tin and lead, chemicals that are still unknown to the Kenge population? [31-40].

And yet, incineration and burial in the ground are common practices as methods of management of WEEE by residents of the city of Kenge, gold Potelle [21] notes that the inadequate treatment of e-waste can cause contamination of air, water and soil by lead and its inorganic compounds. During the incineration of waste, the lead used for welding can be volatilized in the air, and the lead oxide of the cathode ray tube is soluble and can contaminate the soil and water if it is buried. In addition, the Toxicology Directory Service (2007) suggests that lead is chronically toxic to humans. It is bio accumulative and has adverse effects on the digestive system, nervous system, blood system and kidneys that these people still do not know. In addition, the practice of incinerating WEEE has become the home of the inhabitants of Kenge while PVC plastic used in electronic equipment for the manufacture of the housing and targeting, although recyclable, notes Potelle [21], disadvantageous environmental important when there are emissions of dioxins and furans during its manufacture and its incineration. In addition, despite the harmless nature of certain components before the end of life of the EEA, components such as the a metal frame which stiffens the equipment is mainly composed of ferrous metals and aluminum while the plastic shell which protects, as the key are compounds of plastics of various kinds in particulars has Ceylon it rile butadiène styrene (ABS) and polyvinyl chloride (PVC) whereas chimney are incorporated to improve their perform has that, in particular flame retardants (flame brimmed) [20]. Yet, incorporation of these additives in plastics makes their recyclability use complex or impossible and, in case of incineration temperature insufficiently highest, the fireproof brominated produce dioxins and furans [21] as well as the cables in the computer that allows not to enter into energy different components and trans lets born there between are composed of stall (General copper) and covered with a plastic sheath (PVC added retardants flames) whose consequences harmful than locals Kenge ignorant have already been mentioned.

And, the people of the city of Kenge do not know the drawbacks of lead and mercury, otherwise they would not have adopted behaviors that do not reflect the GER such as throwing WEEE anywhere or giving them away. children to use as a toy or burn them or bury them in the soil as they do. Because, the manufacture of the screen currently uses two technologies: the cathode ray tube screen and the flat screen. $L$ has first technology mainly uses glass that incorporates lead [21] has stigmatized the adverse effects on air, water and soil and its corollaries on human health reported by the Department of Toxicological Inventory (2007). And the second technology, flat screen, use mercury who is bio a cumulable posed adverse effects when main went through the respiratory tract as for vapor or through the skin, has severe effects nervous system absorbs this antral peripheral (Service of toxicological inventory, 2008). What's more, it volatilizes to temperature and water, it for methyl mercuric who told the sediment and the class in elements. Incineration and buries to uncontrolled waste electronics contribute so to contamination of the surrounding environment by mercury (Service that toxicological directory, 2008) [41-46].

Presumably, the population of our study area yet know the danger contained in rechargeable batteries contain several elements common precious one's are Nickel, Cadmium or Lithium or Nickel Cadmium and either of nickel and metal hydride, or else of lithium and ion, of lithium polymer (Roberge, 2010). Cadmium, although valuable, is bio accumulative and absorbed mainly by the respiratory and digestive tracts. Acute cadmium contamination can lead to respiratory problems, digestive problems and kidney failure. Its chronic effects mainly affect the kidneys and is carcinogenic (Directory of Toxicology, 2006). And, Antimony used in some electronic components in addition to be a flame retardant and a solder component. This product can be absorbed by the respiratory tract, the skin and the digestive tract, and it causes problems in the skin and mucous membranes, the digestive system and the liver (Department of toxicological repertoire, 2009a). Butalso, hexavalent 
chromium (Chrome IV) was used widely as a plating agent for the treatment of ferrous metals, but its use tends to decrease due to its toxicity. Both its incineration and uncontrolled burial are sources of chromium VI emissions into the environment. It has effects that are highly toxic to humans during chronic exposure, including respiratory problems, liver and kidney damage, increased risks of cancer, and changes in genetic background (Toxicology Inventory Service, 2009).

It turns out that all the methods, or practices, of WEEE management employed by the inhabitants of the city of Kenge are likely to harm human health either by permanent exposure to the toxic chemical elements emitted into the atmosphere, into water, in the soil, or by contamination of food in the food chain. In short, these irresponsible behaviors are dangerously polluting the human environment to the point of exposing it to many dangerous conditions and death because of the ignorance of GER that could help mitigate the adverse effects of toxicity. chemical compounds contained in end-of-life EEE components.

As elsewhere in DR Congo, there are no regulations of specific WEEE and it is not either a member of some such agreements on the Basel Convention adopted in 1989 and entered into force in 1992, has set itself the task of controlling the transboundary movement of hazardous wastes and their disposal in order to reduce the volume of such movements and to reduce the adverse effects on human health and the environment, so that these movements must be assessed before their through the information provided to the States concerned (Secretariat of the Basel Convention, 2012). It is also not a member of Bamako, which was adopted in 1991 and came into force in 1998, which deals with the prohibition of the import of hazardous waste into Africa and governs the control of their transboundary movements in the country. continent (Basel Convention Secretariat, 2012), to name just two examples.

\section{Link E-Waste, Food, Energy, Water and Health: Process of Transfer}

Once thrown on the ground, e-waste can release toxic substances into the atmosphere, for example by incineration, exposing humans to certain diseases such as respiratory diseases, otherwise, staying on the ground. Electronic waste is a real danger to the environment and public health as electronic devices contain relatively harmful products such as mercury, lead or phosphorus. In case of mismanagement, these elements are released into the atmosphere causing significant damage to humans and the environment (Cordier, 2003). On the other hand, we know that rainfall and irrigation are the main sources of soil water. Part of it is evacuated by evaporation or surface runoff and another part enters the soil and then goes either to the roots of plants or by gravity to the deep horizons and water tables. However, during these transports the water is charged in elements in dissolved traces of chemical substances, sometimes harmful and toxic, manufacturing components of IAS that can reach surface water by runoff, or groundwater percolation. And, part of this solution, can be absorbed by plants. Because, for their nutrition, the plants need water and mineral salts which it digs into the soil, thanks to its roots the water and the mineral salts, absorbed together, form what is called the sap brut- whose end of each carries many absorbent hairs which are extensions of the superficial cells, thanks to which this absorption is done so that these toxic substances are accumulated in the plant, or in some of its organs to like leaves, fruits, roots, bark.

However, to store the calorific energy useful for its functions, man must feed on plants or animals. However, the contamination of humans is through its permanent exposure to the toxic substance, in the atmosphere for example, or its position in the food chain: it can ingest toxic substances by directly consuming the plant that has accumulated toxic substances. toxic substances, or indirectly by eating an animal that has consumed this plant. Or, it can be contaminated by drinking, or by using for its cooking, water from the groundwater or contaminated surface water. At final, man risks of many diseases from these e-waste(Table 5).

\section{Conclusion and Recommendations}

The purpose of this research was to demonstrate the link between e-waste, food, energy, water and health. It was a question of identifying more specifically the producers of e-waste in the town of Kenge and estimate the volume, check the knowledge and practical skills of the local population vis-à-vis the GER of e waste and, finally, to identify the health and environmental impacts of their management practices. It emerges from the analysis of the situation that the phones (45\%), positions radios (26\%), television sets $(13 \%)$, computers $(8 \%)$, DVD players $(5 \%)$ and printers $(3 \%)$ are the most widely used EEE for kenge residents. And, between $87-$ $93 \%$ of residents used an average of 6-8 phones between 2007 and 2017, including 4-6 phones have been converted into e-waste (either in total 533. 448-800. 172 phones). What Represented e 16 tons to 24 tons of WEEE, is 0.10 to $0.16 \mathrm{~kg}$ of e-waste dumped by individual in the environment. This behavior has less than 5 chances out of 10,000 to correspond to environmentally sound management (ESM) and to know the risks that e-waste poses for health and the environment, if not, to simply make the environment dirty.

Therefore, this e-waste can pollute the soil and sub-soil, the atmosphere and expose the man has a lot of diseases from the evaporation of harmful substances and heavy metals manufacturing components EEA. In addition, they were still able to pollute the soil, accumulate in the plant through raw sap or contaminate surface water and groundwater. The man according to his position in the food chain can therefore use either the water or the contaminated plant and thus compromise his health through ignorance of GER. It is therefore recommended to the provincial authority to establish an e-waste program management, in order to make the collect, recover and recycle WEEE and raise awareness about PRE while accompanying these actions with a consequent regulation. These interventions are considered necessary to stem the scourge soil, 
water and air pollution that threatens the health of the thousands of souls living in the City of Kenge.

\section{References}

1. Luwesi, CN (2017) T Industrial technologies and innovations in the health sciences ed. Kenge: Section S ealth C ommunity D epartment management of health institutions, ISTM-MRP Kenge, DR Congo.

2. Boyer R (2001) The Economist Faced with Innovations That Make History: The Relationship Between History and Theory. Economic Review 52(5): 1065-1115.

3. (2012) Secretariat of the Basel Convention, SCB WEEE in Africa: State of play - Results of the e-waste africa Program of the Basel Convention. Basel: Secretariat of the Basel Convention (SCB).

4. Streicher Porte M (2006) Material flow analysis and economic evaluation as design tools for the recycling of waste electrical and electronic equipment, the recycling of personal computers. $\mathrm{PhD}$ thesis. Zurich: Swiss Federal Institute of Switzerland s Technology s Zurich, Switzerland.

5. Thieffry P (2011) Environmental law of the European Union. Brussels: Ed. Bruylant, Belgium.

6. ADEME (2010) Annual report: electrical and electronic equipment (year 2009).

7. ADEME (2008) Summary: Waste Electrical and Electronic Equipment (WEEE) In: S Schlitz, M Stevenin, A Ait Hmad, T Mariage (Eds.) International Waste Traffic. Liège: Free University of Liège, Belgium.

8. Zmirou D, Beausoleil M, De Coninck P (1994) Waste and polluted soil In: M Guérin, P Gosselin.

9. Cedric G (2011) Ecological impacts of Information and Communication Technologies (EDP Sciences). Available on the website of the ÉcoInfo Group of the CNRS.

10. EMPA (2007) UN initiative to improve e-waste recycling, Media release, 7 March. See also the article "Waste Electrical and Electronic Equipment".

11. Hagemann S (2009) Technologies for the stabilization of elemental mercury and mercury-containing wastes. Gesellschaft fur Anlagen- und Reaktorsi Cherheit (GRS). GRS Report 252.

12. (1975) Journal official, Law $n^{\circ} 75-633$ of July 15 th, 1975 relating to the elimination of the waste and the recovery of materials, published in the JORF of July 16th, 1975. Paris: Official Journal of the French Republic (JORF).

13. CENI (2014) Report of Topographic Surveys of Electoral Sites, Kenge.

14. Dagnelie P (1986) Theory and statistical methods. Agronomic applications 2. Gembloux: The Agronomic Press of Gembloux, Luxembourg.

15. Lamotte M (1971) Introduction to statistical methods in biology. Paris: Masson \& Co.

16. Bailleul J (2010) Report Computer Reuse? In Ordi 2.0

17. Luwesi, CN, Nutsukpui, AA, Wambua, PP and Nkpeebo, AY (2018) Societal marketing and resource mobilization: Communication and engagement methods that work for water. In: A Beyene, CN Luwesi (eds.), Innovative Water Finance in Africa - A Guid e for Water Managers, Sweden, 1: 114139.

18. Alainet P (2010) Exposure to toxic metals and public health in developing countries.

19. Silicon Valley Toxic Coalition (2004) Poison PCs and toxic TVs.

20. Lassalle M (2011) The end of life of computer equipment: a comparison of management methods in France and Québec and the determination of success factors. Master of the environment (M. Env.). Quebec: University Center for Environmental Education, University of Sherbrooke, Longueuil, Canada.
21. Potelle D (2009) Information and communications technology residues.

22. AEA Technology (1997) Recovery ofWEEE: Economic and Environmental Impacts (Recovery of Electronic Waste: Consequences on the Economy and the Environment). Final Report written for the European Commission DG XI, June 1997. Brussels: National Environmental Technology Center, Belgium.

23. Annepu RK (2012) Sustainable Solid Waste Management in India. In: Columbia University Earth Engineering Center (eds), Advancing Sustainable Waste Management pp. 189.

24. A Ntonius R (2004) Initiation to SPSS statistical analysis software. SOC4206 course notes: Laboratory and various exercises. Montreal: Department of Sociology, University of Quebec at Montreal (UQAM), Canada.

25. Biagiotti I (2011) The big global market for waste. Courrier de la Planète, International Alternatives 9.

26. Breton S (1971) From the principle. The contemporary organization of the thinkable. Paris: Editions of the Cerf.

27. Brunault L (2011) Basel Convention and International Trade: An Empirical Analysis of Transboundary Movements of Waste, End of Studies Project. Paris: Schools of Paritech Bridges, Mines ParisTech and Cerna.

28. Chalot F (2004) Summary and analysis of actions related to waste. From upstream to downstream: the emergence of a waste management sector adapted to African cities, $26 \%$.

29. Chollot (2005) The knowledge of waste electrical and electronic equipment, INRS, Ed 5029.

30. Carroll C (2008) High-Tech waste. National Geographic France, No 100.

31. Coby S, Wong C, Wu S, Nurdan C, Duzgoren Aydin S (2006) Trace metal contamination of sediments in an e-waste processing village in China. Environ Pollut. 145(2): 434-442.

32. Cordier S (2003) Environment and public health: foundations and practices. EDISEM pp. 398-440.

33. De Bono A, Giuliani G, Kluser S, Peduzzi P (2005) Electronic waste, the hidden face of the rise of information and communications technologies. Nairobi: UNEP, Kenya.

34. Dorion JF (2008) Management of electronic products in Quebec: The case of television screens and computer monitors. Quebec: Canada p. 72.

35. Grammont L (2003) Inferential Statistics Course, Bachelor of Economics and Management. Saint-Etienne: University Saint-Etienne, France.

36. (2008) Greenpeace. Illegal electronic waste "offered" in Ghana. Amsterdam: The Netherlands. Available on the website: www. greenpeace.org (Last visit on March 24, 2013).

37. (2007) Journal of the Environment. China, the treatment of WEEE, pollution source.

38. Kuehr R, Williams E (2003) Computers and the environment Understanding and managing their impacts. Boston: Kluwer Academic Publishers.

39. Kuper J Hojsik M (2008). Poisoning the poor: Electronic waste in Ghana Greenpeace report. Amsterdam, The Netherlands.

40. Leroy JB (nineteen eighty-one) Waste and its treatment: industrial and household solid waste. Paris: University Presses of France (PUF)

41. L undgren K (2012) The overall impact of e-waste: Addressing the challenge. Geneva: International Labor Office, Program on Safety and Health at Work and the Environment (SafeWork). Sectoral Activities Department (SECTOR)

42. Luwesi CN, Obando JA, Shisanya CA (2017) The impact of awaking micro-climate on Muooni farmers of Kenya. Agriculture 7 (3):1-20.

43. Schlitz S, Stevenin M, Ait Hmad A, Marriage T (2010) International waste traffic. Liège: Free University of Liège, Belgium. 
44. Streicher Porte, Widmer R Jain, A Bader HP, Scheidegger R, Kytzia S (2005) Main drivers of the e-waste recycling system: assessment and modeling of electronic waste in the informal sector in Delhi. Impact Assessment Review pp. 491.

\section{ISSN: 2574-1241}

DOI: 10.26717/BJSTR.2019.18.003144

Cush Ngonzo Luwesi. Biomed J Sci \& Tech Res

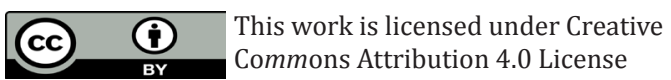

Submission Link: https://biomedres.us/submit-manuscript.php
45. Tiltmann / Schüren (Hg) (1994) Recycling praxis Elektronik (electronics recycling practice). Cologne: Ed. Verlag TÜV Rheinland, Germany.

46. (2013) Administrative Census 2013. Kenge: Town Hall of Kenge City, Kwango Province, Democratic Republic of Congo.

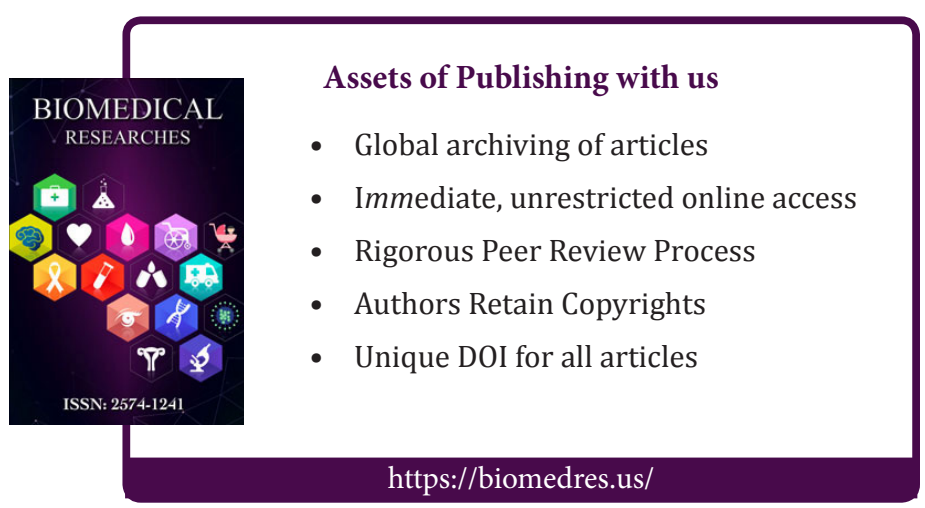

